Emissões de Óxido Nitroso sob Cobertura de Pastagem numa Topossequência em Seropédica, RJ

\author{
Pinheiro, E. F. M.;* Santos, C. A.; Silva, S. N.; Alves, B. J. R; Campos, D. V. \\ B.; Ceddia, M. B.
}

Rev. Virtual Quim., 2018, 10 (6), 1809-1827. Data de publicação na Web: 17 de dezembro de 2018

http://rvq.sbq.org.br

\title{
Nitrous Oxide Emissions Under Pasture Coverage in a Toposequence in Seropédica, RJ
}

Abstract: Nitrification and denitrification are the processes that give rise to the emissions of nitrous oxide $\left(\mathrm{N}_{2} \mathrm{O}\right)$ from the soil to the atmosphere, both processes being dependent on the availability of oxygen, but in opposite redox conditions. These reactions are affected by soil characteristics such as aeration, temperature, humidity, soil reaction, fertilizers, available organic matter, among others. The objective of this work was to evaluate the $\mathrm{N}_{2} \mathrm{O}$ emissions in a Brachiaria humidicola pasture, distributed in a toposequence in Seropédica, RJ. The area has variation of soil class and drainage influenced by topography. The experiment was conducted in the Milk Cattle Sector of the Federal Rural University of Rio de Janeiro (UFRRJ). The evaluated treatments were pasture planted under a Red-Yellow Argisol and pasture planted under the Gleissolo soil. The experimental design was in randomized blocks, with four replications and two treatments. The $\mathrm{N}_{2} \mathrm{O}$ emissions were evaluated using static chambers. Physical fractionation, aggregate weighted mean diameter (AMD) and water saturated pore space (EPSA) were also determined to understand the mechanisms related to $\mathrm{N}_{2} \mathrm{O}$ emission. The highest $\mathrm{N}_{2} \mathrm{O}$ fluxes were observed on the third and eighth day of sampling in the Red-Yellow Argisol (41 $\mu \mathrm{g}$

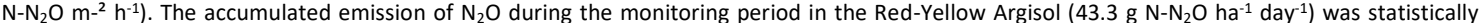
significant in relation to Gleissolo (2.4 g N-N $\left.\mathrm{O} \mathrm{ha}^{-1} \mathrm{day}^{-1}\right)$. The Gleissolo showed lower soil C input, measured by the free light fraction mass (FLL), and lower AMD. It concluded that, the Red-Yellow Argisol has an eighteen times greater potential to emit $\mathrm{N}_{2} \mathrm{O}$ than Gleissolo. Soil water content, FLL and percentage of stable aggregates in the Red-Yellow Argisol are factors that may be regulating the $\mathrm{N}$ loss pathways by nitrification.

Keywords: Soil organic matter; acrisols; gleysols; soil aggregation.

\section{Resumo}

A nitrificação e a desnitrificação são os processos que dão origem às emissões de óxido nitroso $\left(\mathrm{N}_{2} \mathrm{O}\right)$ do solo à atmosfera, sendo ambos os processos dependentes da disponibilidade de oxigênio, porém em condições redox opostas. Essas reações são afetadas por características do solo, como aeração, temperatura, umidade, reação do solo, fertilizantes, matéria orgânica disponível, entre outros. O objetivo deste trabalho foi avaliar as emissões de $\mathrm{N}_{2} \mathrm{O}$ numa pastagem de Brachiaria humidicola, distribuída numa topossequência em Seropédica, RJ. A área possui variação de classe de solo e drenagem influenciada pela topografia. O experimento foi conduzido no setor de Bovinocultura de Leite da Universidade Federal Rural do Rio de Janeiro (UFRRJ). Os tratamentos avaliados foram pastagem plantada sob Argissolo Vermelho-Amarelo e pastagem plantada sob o solo Gleissolo. $\mathrm{O}$ delineamento experimental foi em blocos ao acaso, com quatro repetições e dois tratamentos. As avaliações das emissões de $\mathrm{N}_{2} \mathrm{O}$ foram realizadas com câmaras estáticas. Também foi determinado o fracionamento físico da matéria orgânica do solo, diâmetro médio ponderado dos agregados (DMP) e o espaço poroso saturado por água (EPSA) para entender os mecanismos relacionados à emissão de $\mathrm{N}_{2} \mathrm{O}$. Os maiores fluxos de $\mathrm{N}_{2} \mathrm{O}$ foram observados no terceiro e oitavo dia de amostragem no Argissolo Vermelho-Amarelo ( $41 \mu \mathrm{g} \mathrm{N}-\mathrm{N}_{2} \mathrm{O} \mathrm{m}{ }^{-2} \mathrm{~h}^{-1}$ ). A emissão acumulada em todo o período de monitoramento no Argissolo Vermelho-Amarelo (43,3 $\mathrm{g} \mathrm{N}^{-\mathrm{N}_{2}} \mathrm{O}_{\text {ha-1 }}$ dia $\left.^{-1}\right)$ foi estatisticamente significativa em relação ao Gleissolo $\left(2,4 \mathrm{~g} \mathrm{~N}-\mathrm{N}_{2} \mathrm{O}\right.$ ha${ }^{1} \mathrm{dia}^{-1}$ ). O Gleissolo apresentou menor entrada de $\mathrm{C}$ no solo, medida pela massa de fração leve livre (FLL) e menor DMP. O Argissolo VermelhoAmarelo tem um potencial dezoito vezes maior em emitir $\mathrm{N}_{2} \mathrm{O}$ que o Gleissolo. O conteúdo de água no solo, a FLL da matéria orgânica do solo e o percentual de agregados estáveis no Argissolo Vermelho-Amarelo são fatores que podem regular as vias de perda de $\mathrm{N}$ por nitrificação.

Palavras-chave: Matéria orgânica do solo; argissolo Vermelho-Amarelo; gleissolo; agregação do solo.

* Universidade Federal Rural do Rio de Janeiro, Instituto de Agronomia-Departamento de Solos, Campus Seropédica, CEP 23890000, Seropédica-RJ, Brasil.

Merika.solos@gmail.com

DOI: 10.21577/1984-6835.20180119 


\section{Emissões de Óxido Nitroso sob Cobertura de Pastagem numa Topossequência em Seropédica, RJ}

\section{Érika Flávia Machado Pinheiro, ${ }^{\mathrm{a}, *}$ Camila de Almeida Santos, ${ }^{\mathrm{a}}$ Séphora Neves da Silva, ${ }^{a}$ Bruno José Rodrigues Alves, ${ }^{\text {b }}$ David Villas Boas de Campos, ${ }^{\mathrm{c}}$ Marcos Bacis Ceddia ${ }^{\mathrm{a}}$}

aUniversidade Federal Rural do Rio de Janeiro, Instituto de Agronomia, Departamento de Solos, Campus Seropédica, CEP 23890-000, Seropédica-RJ, Brasil.

bEmpresa Brasileira de Pesquisa Agropecuária - Embrapa Agrobiologia, CEP 23891-000, SeropédicaRJ, Brasil.

'Empresa Brasileira de Pesquisa Agropecuária - Embrapa Solos, CEP 22460-000, Rio de Janeiro-RJ, Brasil.

* erika.pinheiro@gmail.com

Recebido em 30 de outubro de 2018. Aceito para publicação em 30 de outubro de XXXX

\section{Introdução}

2. Material e Métodos

2.1. Descrição da área experimental

2.2. Amostragem do óxido nitroso

2.3. Determinação do fluxo de óxido nitroso

2.4. Fracionamento físico da matéria orgânica do solo

2.5. Determinação do diâmetro médio ponderado dos agregados do solo

2.6. Análises estatísticas

\section{Resultados e Discussões}

3.1. Emissão de óxido nitroso sob cobertura de pastagem na topossequência

3.2. Relação entre os fluxos de óxido nitroso e as propriedades do solo

\section{Conclusões}




\section{Introdução}

A agricultura teve início com a recessão do período glacial, em torno de 10.000 anos a.C., quando a população do mundo era de apenas 3 milhões de habitantes. ${ }^{1,2} \mathrm{~A}$ atual população mundial de 7,2 bilhões está projetada para crescer e alcançar cerca de 9,6 bilhões em 2050, de acordo com o relatório lançado pelas Nações Unidas, ${ }^{3}$ que aponta que o crescimento será maior nos países em desenvolvimento. A pergunta é como alimentar uma população crescente aliado à capacidade de produzir alimentos de forma sustentável, garantindo a segurança alimentar, do solo, hídrica e energética e ainda mitigar as mudanças do clima?

A emergência da chamada 'Civilização do Carbono' ou a "Era do C" e as consequências ambientais desse período podem ser facilmente constatadas. ${ }^{1,4} \mathrm{Em} \mathrm{1750,} \mathrm{o} \mathrm{pronto}$ acesso à energia moderna, através de combustíveis fósseis, levou a produção em massa de facilidades modernas a baixo custo. Como resultado, o aumento global da emissão de gás carbônico $\left(\mathrm{CO}_{2}\right)$ foi diretamente proporcional ao aumento do consumo de energia fóssil. De acordo com Silva e Arbilla, ${ }^{4} \mathrm{o}$ aumento nas concentrações de $\mathrm{CO}_{2}$, atingindo valores maiores que 400 ppm (sendo que o valor na época préindustrial era de $285 \mathrm{ppm}$ ), são o início de uma mudança muito maior que envolve os ciclos biogeoquímicos como os do carbono, nitrogênio, fósforo e enxofre, ciclos da água e a extinção de espécies. Neste contexto, cresce a evidência do homem como uma força geológica, no impacto e na modificação do planeta. ${ }^{4}$ O Antropoceno, conhecido também como a 'Época dos Humanos', surge como uma nova época com características totalmente diferentes do Holoceno. Esse novo termo foi estabelecido para enfatizar o papel preponderante do homem não somente na geologia, mas na ecologia, química e nas relações políticas e econômicas. ${ }^{4}$
As emissões antrópicas de gases de efeito estufa (GEE) ocorrem em vários setores de diferentes atividades. Ao contrário de países industrializados, no Brasil, a maior parcela das emissões de $\mathrm{CO}_{2}$, óxido nitroso $\left(\mathrm{N}_{2} \mathrm{O}\right)$ e metano $\left(\mathrm{CH}_{4}\right)$ provêm da agropecuária. ${ }^{5} \mathrm{O}$ país possui mais de 172 milhões de hectares de pastagens detendo um rebanho com mais de 218 milhões de cabeças de gado. ${ }^{6} \mathrm{~A}$ agropecuária contribui com $35 \%$ das emissões nacional de GEE, onde $56 \%$ dessa emissão são provenientes do metano entérico, que é produzido pelo processo digestivo dos herbívoros ruminantes no rúmen e $18 \%$ pelo $\mathrm{N}_{2} \mathrm{O}$ através de emissões diretas e indiretas, como a fertilização nitrogenada e as excretas de animais (fezes e urina) depositados nas pastagens. ${ }^{5}$ Esses números mostram a importância da pecuária nas emissões de GEE.

A fermentação do alimento ingerido no rúmen é um processo anaeróbio denominado fermentação entérica, sendo mediada pela população microbiana ruminal, em que os carboidratos celulósicos são convertidos em ácidos graxos de cadeia curta, os quais são utilizados pelo animal como fonte de energia. As bactérias metanogênicas obtêm energia para seu crescimento ao utilizar o $\mathrm{H}_{2}$ para reduzir $\mathrm{o} \mathrm{CO}_{2} \mathrm{e}$ formar metano, o qual é eructado ou exalado para a atmosfera. ${ }^{7} \mathrm{~A}$ fermentação entérica contribui com mais de 89 \% das emissões de $\mathrm{CH}_{4}$ no Brasil. ${ }^{8} \mathrm{O}$ fator de emissão (FE) para bovinos de corte é de 56 $\mathrm{kg} \mathrm{CH}$ animal $^{-1}$ ano $^{-1}$, 9 multiplicando esse valor pelo rebanho brasileiro, em um ano o Brasil emite, aproximadamente, 12,2 toneladas de $\mathrm{CH}_{4}$ pela fermentação entérica. Alguns estudos mostram que a melhoria das condições das pastagens pode reduzir $10 \%$ dessa emissão, além da adoção de sistemas alternativos, como a integração lavourapecuária e sistemas silvipastoris. ${ }^{10,11}$

A maior parte do $\mathrm{N}_{2} \mathrm{O}$ na pecuária vem das excretas dos animais onde predomina o sistema extensivo e uma pequena parte pela fertilização das pastagens e do solo. De acordo com o Painel Intergovernamental sobre Mudanças Climáticas (IPCC), ${ }^{9}$ as excretas contribuem com $2 \%$ das emissões 
desse gás e a fertilização ou decomposição dos resíduos vegetais com $1 \%$.

A nitrificação e a desnitrificação são os processos que dão origem às emissões de $\mathrm{N}_{2} \mathrm{O}$ do solo à atmosfera, ${ }^{12,13}$ ambos os processos dependentes da disponibilidade de oxigênio, porém em condições redox opostas. ${ }^{13}$ Por ser um processo aeróbio, solos bem drenados favorecem a nitrificação, enquanto solos saturados com água favorecem a desnitrificação. Porém, a adequada disponibilidade de água e de temperatura é importante para aperfeiçoar o processo. ${ }^{14}$ Por outro lado, muitos organismos do solo podem desnitrificar, desde que ocorram condições anaeróbicas no solo, sendo a temperatura um fator de grande importância. ${ }^{13,15}$ A nitrificação e a desnitrificação ocorrem concomitantemente com o processo de mineralização do $\mathrm{N}$ orgânico do solo. ${ }^{16} \mathrm{~A}$ mineralização aeróbica do N-orgânico é chamada de amonificação (ou mineralização do N) que como produto final resulta em amônia, que reage com a água, estabelecendo-se as seguintes reações de equilíbrio, conforme a equação $1:{ }^{17}$

$$
\mathrm{NH}_{3} \text { (gás) }+\mathrm{H}_{2} \mathrm{O} \rightleftharpoons \mathrm{NH}_{3} \text { (aq) }+\mathrm{H}_{2} \mathrm{O} \rightleftharpoons \mathrm{NH}_{4}{ }^{+}+\mathrm{OH}^{-} \quad \text { Eq. } 1
$$

O nitrogênio pode perder-se do solo também por volatilização $\left(\mathrm{NH}_{4}^{+}\right)$, por processo inorgânico, em valores de $\mathrm{pH}$ acima de 7 (Figura 1). No solo $0 \quad \mathrm{NH}_{4}$ é biologicamente oxidado a nitrato $\left(\mathrm{NO}_{3}{ }^{-}\right)$. $\mathrm{O}$ processo de nitrificação é iniciado com a oxidação do $\mathrm{NH}_{4}{ }^{+}$a nitrito $\left(\mathrm{NO}_{2}\right)$ por bactérias do gênero Nitrosomonas, seguido da oxidação do $\mathrm{NO}_{2}^{-}$a $\mathrm{NO}_{3}^{-}$por bactérias do gênero Nitrobacter. Os gases $\mathrm{N}_{2} \mathrm{O}$ e $\mathrm{NO}$ são subprodutos desta reação. As bactérias nitrificadoras são obrigatoriamente aeróbicas e utilizam o $\mathrm{O}_{2}$ como aceptor de elétrons. A desnitrificação é o processo de redução biológica do $\mathrm{N}$-nitrato, ou N-nitrito, para $\mathrm{N}_{2} \mathrm{O}$, NO ou até mesmo $N_{2}$. A desnitrificação, juntamente com a volatilização da amônia, constitui as mais importantes vias de perdas gasosas de $\mathrm{N}$ no solo. ${ }^{18}$

Tanto as reações de nitrificação quanto as de desnitrificação são afetadas por características do solo, como aeração, temperatura, umidade, reação do solo, fertilizantes, matéria orgânica disponível, relação carbono/nitrogênio $(\mathrm{C} / \mathrm{N})$ e a presença de fatores tóxicos aos microrganismos..$^{20-24}$

A emissão de GEE na agropecuária é bastante acentuada, visto a grande área de pastagem no Brasil, que na maioria das vezes está em elevado estágio de degradação. ${ }^{25} \mathrm{As}$ áreas de pastagens degradadas podem levar a um maior período do animal no pasto, contribuindo por uma maior emissão de gases ao longo desse período. Uma alternativa para minimizar essas emissões é melhorar o manejo da pastagem, que influenciará no aumento da qualidade da forrageira, ampliando o desempenho animal e, consequentemente, reduzindo o período de abate e a emissão por quilo de carne diminuiria. Cabe ressaltar que o desenvolvimento da pastagem pode acarretar em um dreno de metano e óxido nitroso, através do estoque de carbono e também de nitrogênio no solo. Isso torna o ciclo de vida da produção de leite mais positivo, ou seja, com menores emissões de $\mathrm{N}_{2} \mathrm{O}$ e $\mathrm{CH}_{4}$ e maior fixação de $\mathrm{C}$ e $\mathrm{N}$ no solo. ${ }^{25}$ 


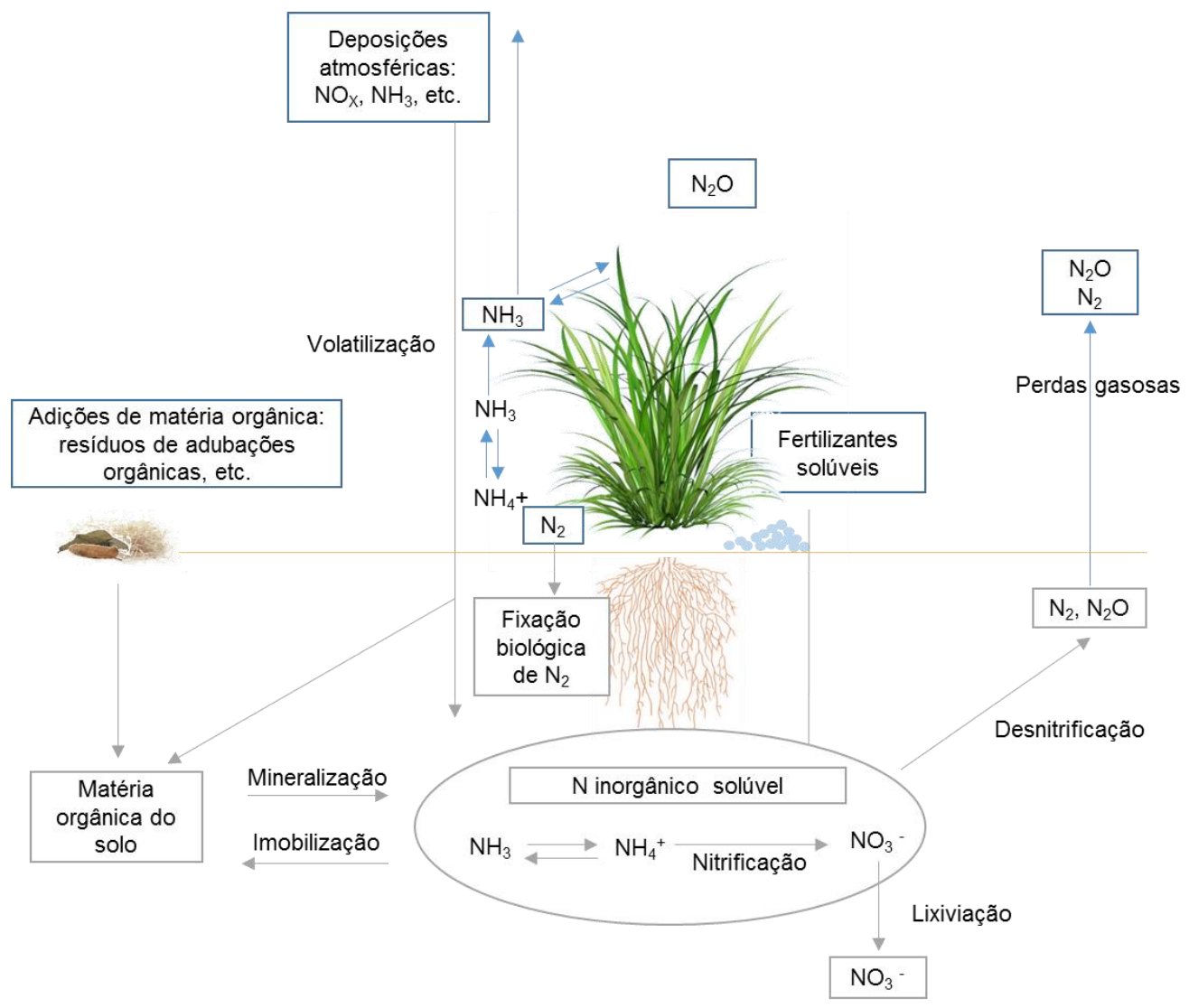

Figura 1: Ciclo do nitrogênio no sistema solo-planta-atmosfera. Adaptado de Cantarella. ${ }^{19}$

Os estudos feitos em condições de clima temperado têm mostrado que o uso de um único fator de emissão não seria adequado, pois diferenças nas emissões de $\mathrm{N}_{2} \mathrm{O}$ foram encontradas entre diferentes culturas, não necessariamente por efeito da cultura, mas em função do tipo de fertilizante, tipo de solo etc. ${ }^{25}$ Poucos estudos sobre emissão de $\mathrm{N}_{2} \mathrm{O}$ estão disponíveis para as regiões tropicais, ${ }^{14}$ e a maioria dos resultados obtidos sugerem que a emissão de $\mathrm{N}_{2} \mathrm{O}$ ocorre em magnitude bem menor do que aquelas que alimentaram as bases de dados usadas pelo IPCC.

O Objetivo desse trabalho foi avaliar as emissões de $\mathrm{N}_{2} \mathrm{O}$ numa pastagem de Brachiaria humidicola distribuída numa topossequência em Seropédica (RJ). A área com cobertura de pastagem possui variação de classe de solo (Argissolo VermelhoAmarelo e Gleissolo) e drenagem influenciada pela topografia.

\section{Material e Métodos}

\subsection{Descrição da área experimental}

O experimento foi conduzido numa topossequência ou catena, que é o nome que se dá a uma sequência de solos que pode ser observada ao longo de uma encosta. A área experimental está localizada no setor de Bovinocultura de Leite da Universidade Federal Rural do Rio de Janeiro (UFRRJ), Campus Seropédica (RJ) (Figura 2). 


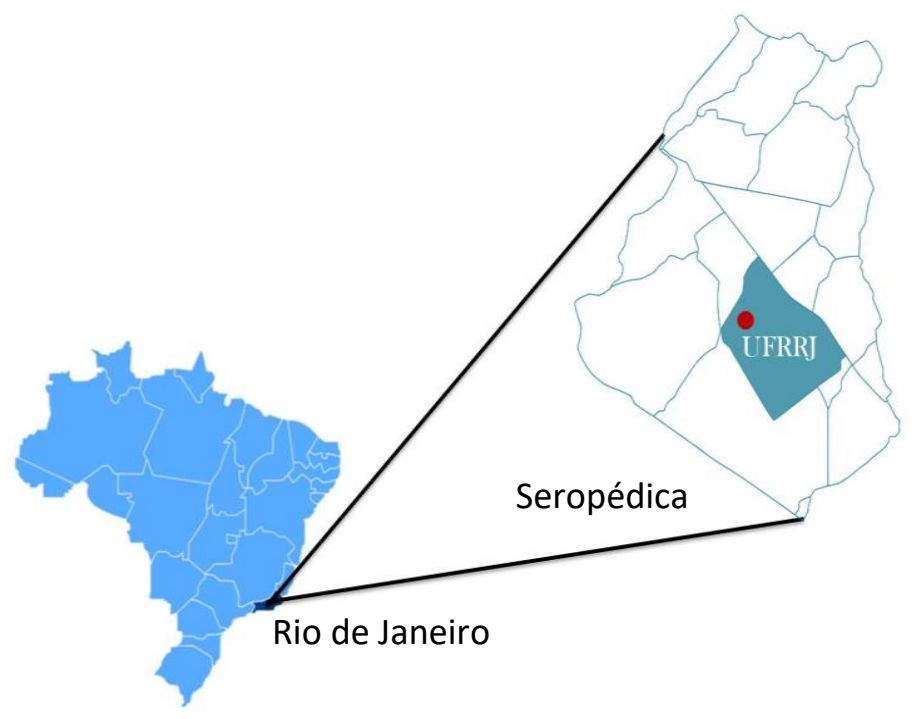

Figura 2. Localização geográfica da área experimental no Setor da Bovinocultura Leiteira, na UFRRJ, Campus Seropédica (RJ)

A topossequência sob cultivo de pastagem de Brachiaria humidicola apresenta três classes de solos. No terço superior do relevo é constituído de Argissolo Vermelho-
Amarelo, no terço médio apresenta o solo Planossolo e na parte inferior do relevo, apresenta a classe Gleissolo (Figura 3).

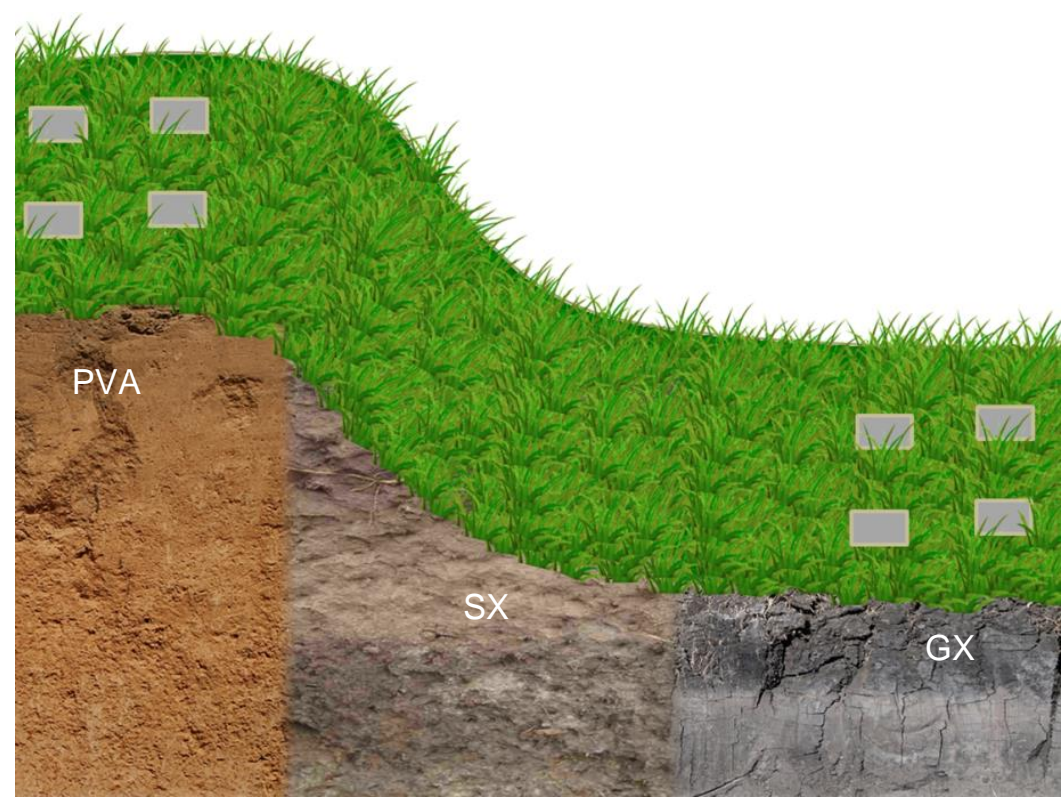

Figura 3. Toposequência destacando as classes de solos (PVA - Argissolo Vermelho-Amarelo, SX- Planossolo Háplico e GX- Gleissolo) e os pontos de amostragens com o detalhe das câmaras coletoras estáticas para a coleta do gás óxido nitroso 
A análise granulométrica dos solos estudados está apresentada na Tabela 1. 0 Argissolo Vermelho-Amarelo possui textura franco-arenoso enquanto que o Gleissolo apresenta textura areia franca.

Tabela 1. Análise granulométrica $\left(\mathrm{g} \mathrm{kg}^{-1}\right)$ dos solos Argissolo Vermelho-Amarelo e Gleissolo, numa toposequência, sob cobertura de pastagem, nas profundidades de 0-10, 10-20 e 20-30 $\mathrm{cm}(\mathrm{n}=4)$

\begin{tabular}{|c|c|c|c|}
\hline \multirow[t]{2}{*}{ Classes de solo } & Areia & Silte & Argila \\
\hline & \multicolumn{3}{|c|}{-- } \\
\hline & \multicolumn{3}{|c|}{ 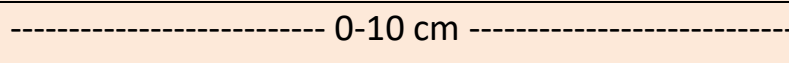 } \\
\hline Argissolo Vermelho-Amarelo & 836 & 67 & 97 \\
\hline \multirow[t]{2}{*}{ Gleissolo } & 770 & 102 & 128 \\
\hline & \multicolumn{3}{|c|}{ - 10-20 cm --- } \\
\hline Argissolo Vermelho-Amarelo & 815 & 70 & 115 \\
\hline \multirow[t]{2}{*}{ Gleissolo } & 756 & 105 & 139 \\
\hline & \multicolumn{3}{|c|}{ 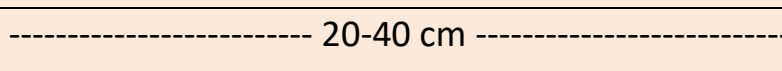 } \\
\hline Argissolo Vermelho-Amarelo & 802 & 69 & 129 \\
\hline Gleissolo & 794 & 94 & 112 \\
\hline
\end{tabular}

Dentre as classes de solo de maior expressão no Brasil, os Argissolos ocupam a segunda posição, representando $26,8 \%$ da extensão e distribuição dos solos do país. ${ }^{26}$ Esta classe caracteriza-se por solos minerais, não hidromórficos e profundos, apresentando um acúmulo de argila no horizonte B. ${ }^{27} \mathrm{~A}$ capacidade de retenção de água pela superfície da argila devido à presença de cargas nesta fração granulométrica pode influenciar consideravelmente nas emissões dos GEE, uma vez que estas emissões aumentam em condições de maior umidade do solo. Por outro lado, os Gleissolos são solos minerais, hidromórficos, apresentam um horizonte com cores cinzentas (horizonte glei), imediatamente abaixo do horizonte $A$, ou que começa dentro de $50 \mathrm{~cm}$ da superfície, tornando-se um indicativo de formação em ambiente redutor virtualmente livre de oxigênio dissolvido em razão da saturação por água durante um longo período do ano. Esta classe de solo ocupa apenas $4,7 \%$ do território nacional. ${ }^{26,27}$
Foram avaliados os seguintes tratamentos: a) Pastagem plantada sob Argissolo Vermelho-Amarelo e, b) Pastagem plantada sob Gleissolo (Figura 3). O delineamento experimental foi em blocos ao acaso, com quatro repetições e dois tratamentos $(2 \times 4)$.

\subsection{Amostragem do óxido nitroso}

Em fevereiro de 2013, para a amostragem do fluxo de $\mathrm{N}_{2} \mathrm{O}$, foram instaladas quatro câmaras na posição mais alto do relevo sob solo Argissolo Vermelho-Amarelo e quatro câmaras no terço inferior sob Gleissolo. Foi realizado experimento somente na estação do verão, que é o período de maior precipitação e, consequentemente, maior teor de umidade no solo que pode favorecer com os maiores fluxos de $\mathrm{N}_{2} \mathrm{O}$. Cada câmara era constituída por uma base de metal retangular de $30 \times 25 \mathrm{~cm}$, inserida no solo até $5 \mathrm{~cm}$ de profundidade. Em cada momento da 
amostragem, a base era coberta com uma tampa de metal e selada com grampos de carpinteiro (Figura 4).

As amostras de óxido nitroso foram coletadas por intermédio de seringas de nylon de $20 \mathrm{~mL}$ em dois tempos de incubação, o tempo inicial (TO) e 30 minutos após a incubação (T30), após a coleta, o gás foi diretamente transferido para frascos de vidro de cromatografia $(15 \mathrm{~mL})$, devidamente lacrados para impedir o vazamento e a contaminação das amostras. Os frascos de cromatografia foram selados com rolhas de borracha butírica, recravados com lacres de alumínio. Antes da coleta do gás óxido nitroso, os frascos eram submetidos à vácuo. O vácuo foi realizado com auxílio de um vacuômetro manual até atingir uma pressão de $-80 \mathrm{Kpa}$. As coletas do gás $\mathrm{N}_{2} \mathrm{O}$ foram realizadas sempre no período da manhã (9:00 h), por onze dias consecutivos, que foi iniciado no dia 03 de fevereiro e se estendeu até o dia 13 de fevereiro de 2013.

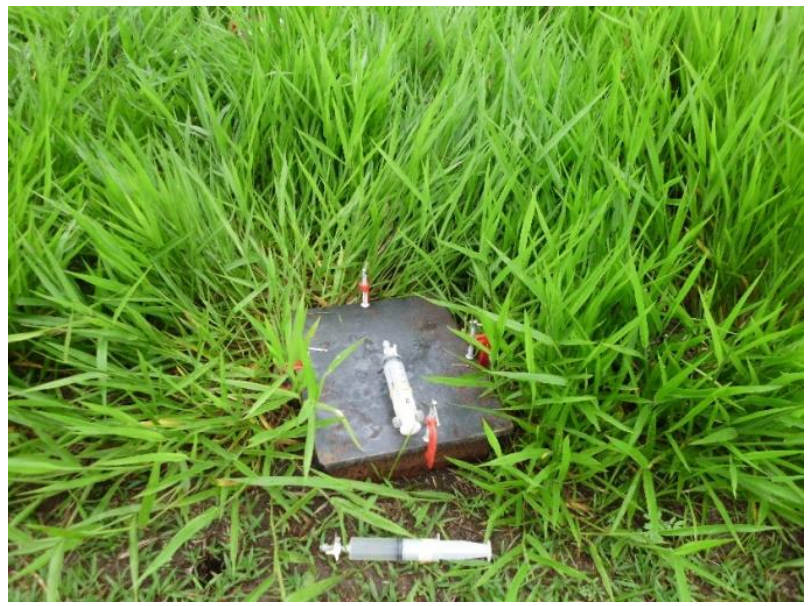

Figura 4. Detalhe da câmara estática fechada no momento da coleta do gás óxido nitroso numa área sob cobertura de pastagem de Brachiaria humidicola em Seropédica, RJ

As amostras de gases coletadas foram enviadas ao Laboratório de Cromatografia da Embrapa Agrobiologia e analisadas por cromatografia gasosa (Perkin Elmer, Auto system XL, Wellesley, MA, USA), utilizando-se uma coluna empacotada com Porapak $Q$ e um detector de captura de elétrons. ${ }^{18}$ Antes de cada conjunto de análises, foram injetadas amostras do padrão da marca Linde (certificado $\mathrm{n}$ - 1310/18) de concentração conhecida de $\mathrm{N}_{2} \mathrm{O}$ (312 ppbv, 400 ppbv, 800 ppbv,1120 ppbv e 10000 ppbv) para o cálculo das concentrações de $\mathrm{N}_{2} \mathrm{O}$ em cada amostra. ${ }^{18}$ As amostras de $\mathrm{N}_{2} \mathrm{O}$ foram analisadas em duplicatas, sendo obtido três repetições para a construção dos pontos da curva de calibração.

Paralelamente à coleta do gás foi determinada a temperatura do solo e do ar com auxílio de um termômetro digital da marca Incoterm (modelo 9791). Também houve amostragem do solo para a determinação da umidade gravimétrica do solo (U), densidade de solo (Ds) e densidade da partícula (Dp), segundo a metodologia da Embrapa. ${ }^{28}$ De posse desses resultados foi calculado o espaço poroso saturado por água (EPSA), conforme proposto por Paul e Clark, ${ }^{29}$ sendo demonstrado na equação 2 :

$$
\% \operatorname{EPSA}=100 *(\mathrm{U} \times \mathrm{Ds}) / 1-(\mathrm{Ds} / \mathrm{Dp})
$$




\subsection{Determinação do Fluxo de $\mathrm{N}_{2} \mathrm{O}$}

Após a determinação da concentração de $\mathrm{N}_{2} \mathrm{O}$ nas amostras por cromatografia gasosa

$$
\mathrm{N}_{2} \mathrm{O}=\delta \mathrm{C} / \delta \mathrm{t} \times \mathrm{V} / \mathrm{A} \times \mathrm{M} / \mathrm{Vm}
$$

Em que: o fluxo de $\mathrm{N}_{2} \mathrm{O}$

$\delta C / \delta t$ é a variação da concentração de $\mathrm{N}_{2} \mathrm{O}$ (ppbv), entre $\mathrm{t}_{0}$ e $\mathrm{t}_{1}$ (hora);

V é o volume da câmara $\left(\mathrm{m}^{3}\right)$;

A é a área da câmara $\left(\mathrm{m}^{2}\right)$;

$M$ é a massa atômica do nitrogênio na molécula de $\mathrm{N}_{2} \mathrm{O}(\mathrm{mg})$ e;

Vm é o volume molecular na temperatura de amostragem $\left(\mathrm{dm}^{3}\right)$.

Com os resultados dos fluxos diários também foi determinada a emissão acumulada de $\mathrm{N}_{2} \mathrm{O}$ (g N-N $\mathrm{N}_{2} \mathrm{O} \mathrm{ha}^{-1}$ dia $^{-1}$ ) ao longo do período avaliado de onze dias.

\subsection{Fracionamento físico da matéria orgânica do solo}

Para entender os mecanismos ligados a emissão de óxido nitroso foi realizado o fracionamento físico da matéria orgânica do solo nas duas posições do relevo, sob Argissolo Vermelho-Amarelo e Gleissolo. Foram abertas trincheiras $(1,0 \times 1,20 \times 1,20$ m) e amostras de terra foram coletadas, das quatro paredes das trincheiras, nas profundidades de $0-10,10-20$ e $20-40 \mathrm{~cm}$. As amostras foram secas ao ar, destorroadas e passadas em peneira de malha de $2 \mathrm{~mm}$ de diâmetro, para obtenção da terra fina seca ao ar (TFSA). As amostras de TFSA foram foram calculados os fluxos de $\mathrm{N}_{2} \mathrm{O}$ (expressos em $\mu \mathrm{g} \mathrm{m}^{-2} \mathrm{~h}^{-1}$ ) pela equação $3:^{18}$

Eq. 3

submetidas ao fracionamento físico por densidade visando à obtenção da fração leve livre (FLL) da matéria orgânica do solo, ${ }^{30-32}$ conforme a metodologia proposta por Sohi e colaboradores. ${ }^{30}$

\subsection{Determinação do diâmetro médio ponderado (DMP) dos agregados do solo}

Amostras indeformadas de terra foram coletadas, nas camadas de 0-5 e 5-10 cm, com auxílio de uma pá reta em minitrincheiras. As mini-trincheiras foram realizadas uma em cada parcela com auxílio de enxadão. Em seguida, as amostras dos agregados do solo foram transferidas para sacos plásticos e armazenadas em caixas de papelão de modo a sofrerem o mínimo de desagregação possível. Essas amostras foram peneiradas utilizando peneiras com malhas de diâmetro de 8 e $4 \mathrm{~mm}$. Para avaliação da distribuição dos agregados, 25 gramas dos agregados com diâmetro entre 4 e $8 \mathrm{~mm}$ foram pesados e submetidos a separação das classes de agregados, em um conjunto de peneiras com malhas de diâmetros $2,1,0,5$, 0,25 , e $0,105 \mathrm{~mm}$, tendo-se utilizado o aparelho Yoder, de frequência igual a 32 ciclos min $^{-1}$ e $4 \mathrm{~cm}$ de amplitude vertical por 15 minutos. Após o peneiramento, obteve-se a proporção de cada classe de agregado, em relação ao total $(25 \mathrm{~g})$, e realizou-se o cálculo do diâmetro médio ponderado (DMP). ${ }^{33}$

$$
\mathrm{DMP}=\Sigma_{\mathrm{i}-1}\left(w \mathrm{w}^{*} \mathrm{~d}\right)
$$

Eq. 4 
Onde:

d é o valor médio dos limites superior e inferior de cada classe $(\mathrm{mm}) \mathrm{e}$;

wi é a proporção de cada classe em relação ao total $(\mathrm{g}) \cdot{ }^{33,34}$

\subsection{Análises estatísticas}

A comparação entre os tratamentos foi realizada através da análise de variância com aplicação do teste $t(p<0,10)$, utilizando o programa estatístico Sisvar 5.6. ${ }^{35}$ Também, foram apresentados os resultados do erropadrão da média considerando as quatro repetições $(n=4)$.

\section{Resultados e Discussões}

\subsection{Emissão de óxido nitroso sob cobertura de pastagem na topossequência}

Os fluxos diários de $\mathrm{N}_{2} \mathrm{O}$ na área de pastagem de Brachiaria humidicola, sob Argissolo Vermelho-Amarelo e Gleissolo são apresentados na Figura 5. Ao contrário do que se esperava, observa-se que ao longo do período avaliado, maiores fluxos de $\mathrm{N}_{2} \mathrm{O}$ foram emitidos na posição mais alta do relevo, sob o solo Argissolo VermelhoAmarelo de drenagem livre. Estudos na literatura mostram que o conteúdo de água no solo regula os processos de nitrificação e desnitrificação do ciclo do nitrogênio. ${ }^{17,18,20-24}$ Durante o período avaliado, em apenas dois dias ocorreu precipitação, de baixa intensidade (menor que $5 \mathrm{~mm}$ ). Em áreas sob o solo Gleissolo, de má drenagem, no terço inferior da topossequência, esperavam-se maiores fluxos de óxido nitroso quando comparado com o terço superior em condições de boa drenagem. O fator relevo influenciando a classe de solo e, principalmente, a drenagem do solo foi um importante mecanismo na perda de $\mathrm{N}_{2} \mathrm{O}$.

Além do teor de umidade do solo, a textura do solo também é um dos fatores que influenciam os processos de perda de $\mathrm{N}_{2} \mathrm{O}$ do solo. ${ }^{17}$ Os solos avaliados, apesar de serem taxonomicamente distintos, possuem textura arenosa, o Argissolo Vermelho-Amarelo possui textura franco-arenosa enquanto que o Gleissolo apresenta textura areia franca (Tabela 1).

Acredita-se que as condições de má drenagem no Gleissolo, influenciada pela topografia, possam estar contribuindo para as perdas de $\mathrm{N}$ na forma de $\mathrm{N}_{2}$, que não é um gás de efeito estufa. A desnitrificação é o processo de redução biológica do N-nitrato, ou $\mathrm{N}$-nitrito, para $\mathrm{N}_{2} \mathrm{O}, \mathrm{NO}$ ou até mesmo $\mathrm{N}_{2}{ }^{17,}{ }^{18}$ Somente no quinto e nono dia o Gleissolo apresentou uma emissão de $\mathrm{N}_{2} \mathrm{O}$ estatisticamente superior ao Argissolo Vermelho Amarelo.

$\mathrm{O}$ maior pico de $\mathrm{N}_{2} \mathrm{O}$ foi observado no terceiro e no oitavo dia de amostragem com valores próximos a $41 \mu \mathrm{g} \mathrm{N}-\mathrm{N}_{2} \mathrm{O} \mathrm{m}^{-2} \mathrm{~h}^{-1}$. Esse resultado pode ser explicado devido à ocorrência de uma precipitação nesses dois dias que pode ter contribuído para elevar o conteúdo de água no solo. Entretanto, de acordo com outros resultados apresentados na literatura, ${ }^{15,18}$ essa perda de $\mathrm{N}_{2} \mathrm{O}$ não é considerada elevada. Valores de emissão de $\mathrm{N}_{2} \mathrm{O}$ acima de $150 \mu \mathrm{g}-\mathrm{N}_{2} \mathrm{O} \mathrm{m}^{-2} \mathrm{~h}^{-1}$ passam a ser consideradas substanciais. ${ }^{18}$

No terceiro dia de monitoramento, o Gleissolo apresentou valores negativos (aproximadamente $-34 \mu \mathrm{g} \quad \mathrm{N}-\mathrm{N}_{2} \mathrm{O} \quad \mathrm{m}^{-2} \mathrm{~h}^{-1}$ ). Esse pico negativo significa que ao invés de emitir para a atmosfera, o solo está retendo $\mathrm{N}_{2} \mathrm{O}$. $\mathrm{Na}$ literatura há vários trabalhos de fluxos negativos de $\mathrm{N}_{2} \mathrm{O}$, esses fluxos são frequentes e substanciais e não podem ser simplesmente atribuídos ao erro experimental. ${ }^{36-39}$ 


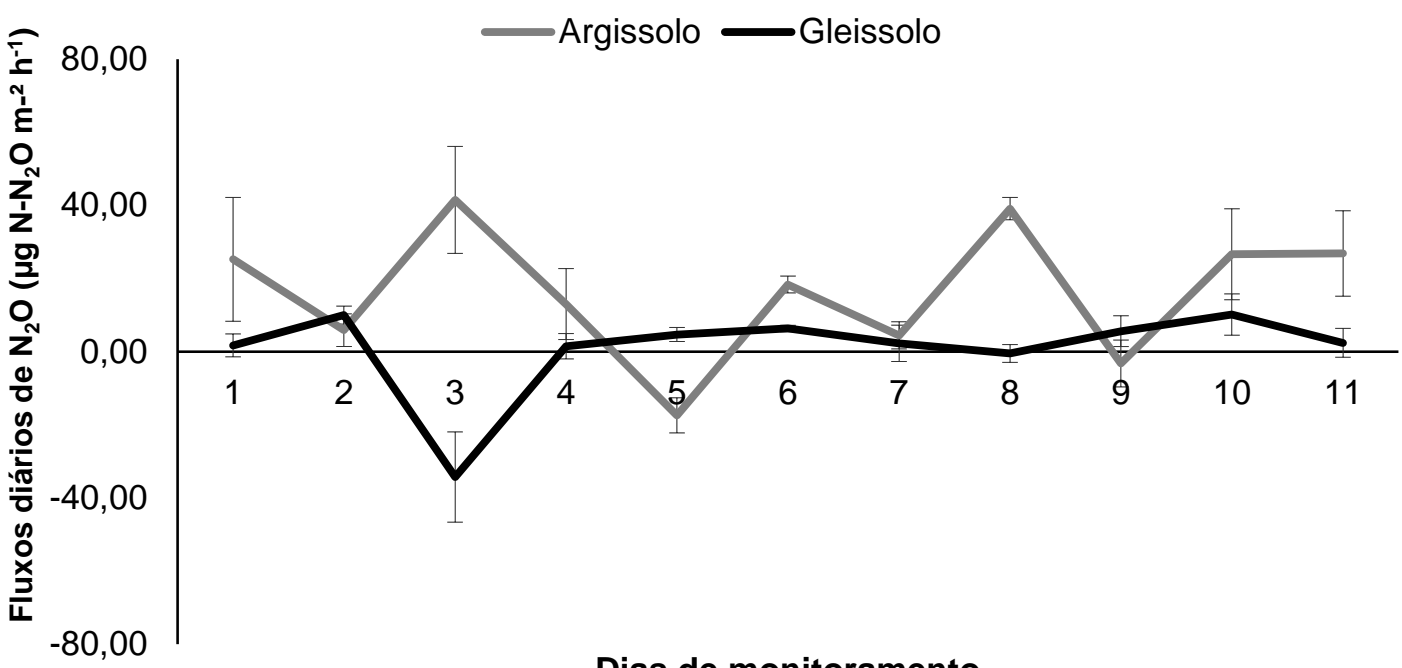

Dias de monitoramento

Figura 5. Fluxos diários de $\mathrm{N}_{2} \mathrm{O}\left(\mu \mathrm{g} \mathrm{N}-\mathrm{N}_{2} \mathrm{O} \mathrm{m}^{-2} \mathrm{~h}^{-1}\right)$ em Argissolo Vermelho-Amarelo e Gleissolo medido, consecutivamente, do dia 03 de fevereiro até 13 de fevereiro de 2013, na estação do verão, sob cobertura vegetal de pastagem, no Setor de Bovinocultura da UFRRJ, Seropédica

(RJ)

Na década de 1970, Blackmer e Bremner mostraram que a capacidade de alguns solos em capturar $\mathrm{N}_{2} \mathrm{O}$ da atmosfera é maior do que a capacidade de produzir $\mathrm{N}_{2} \mathrm{O} .{ }^{36}$ Os solos avaliados por esses autores não foram classificados quanto à classe, porém, possui um teor de argila que varia entre 50 e $550 \mathrm{~g}$ $\mathrm{kg}^{-1}$ de argila. Os solos Argissolo VermelhoAmarelo e Gleissolo avaliados nesse estudo possuem entre 97 e $139 \mathrm{~g} \mathrm{~kg}^{-1}$ de argila, dentro da faixa observada por Blackmer e Bremner. $^{36} \quad$ Algumas publicações subsequentes sustentaram fortemente essa hipótese do solo como fonte de $\mathrm{N}_{2} \mathrm{O}$ atmosférico. $^{38}$ Posteriormente, outros autores têm relacionado fluxos negativos de $\mathrm{N}_{2} \mathrm{O}$ às baixas concentrações de nitrogênio inorgânico (nitrato e amônia) e às elevadas concentrações de oxigênio nos poros do solo, ou seja, condições de aerobiose. ${ }^{34-36}$ De acordo Chapuis-Lardy e colaboradores, ${ }^{38}$ além do conteúdo de água no solo, a temperatura do solo também podem influenciar esse processo. No presente estudo não foi observada diferença estatística significativa entre a temperatura do solo e do ar. Também, não foi observada diferença estatística $(P<0,05)$ na temperatura do solo com relação à classe do solo estudado. A temperatura do solo variou de 25 a $33{ }^{\circ} \mathrm{C}$ ao longo dos onze dias de monitoramento.

\subsection{Relação entre os fluxos de óxido nitroso e as propriedades do solo}

Nesse estudo, foi avaliada a fração leve livre da matéria orgânica do solo como um fator que pode estar relacionado à perda do $\mathrm{N}_{2} \mathrm{O}$ para a atmosfera. Essa fração corresponde à primeira entrada de carbono orgânico no solo, que pode ser utilizada pelos microrganismos como fonte de energia nos processos de transformação do nitrogênio no solo, como por exemplo, a nitrificação e desnitrificação. $\mathrm{Na}$ primeira etapa da nitrificação, o nitrogênio amoniacal é transformado em nitrito, mediado por bactérias do gênero Nitrossomonas e, na segunda etapa, o nitrito é transformado a nitrato, por interferência das bactérias do gênero Nitrobacter. Para que o processo ocorra é necessário que tenha nitrogênio 
mineral no solo, condições de aerobiose, além de carbono orgânico facilmente oxidável. ${ }^{40-42}$

Para explicar as maiores emissões de $\mathrm{N}_{2} \mathrm{O}$ no Argissolo Vermelho-Amarelo, uma hipótese estudada é que essa perda pode estar relacionada à fração leve livre da matéria orgânica do solo (FLL). De acordo com a Figura 6, observa-se que há uma maior massa de FLL no Argissolo Vermelho-Amarelo em comparação ao Gleissolo, principalmente nos primeiros $10 \mathrm{~cm}$ de profundidade, apresentando uma diferença estatística significativa de $6 \mathrm{~g} \mathrm{~kg}^{-1}$ solo $(\mathrm{p}<0,05)$. A FLL é uma fonte de carbono prontamente disponível para os microrganismos. ${ }^{30,31,34}$ Nesse contexto, para que ocorra emissão é necessário que haja uma fonte de energia (FLL da matéria orgânica do solo) para os organismos do solo, sendo assim, os resíduos orgânicos são rapidamente decompostos e o $\mathrm{N}_{2} \mathrm{O}$ pode ser liberado.

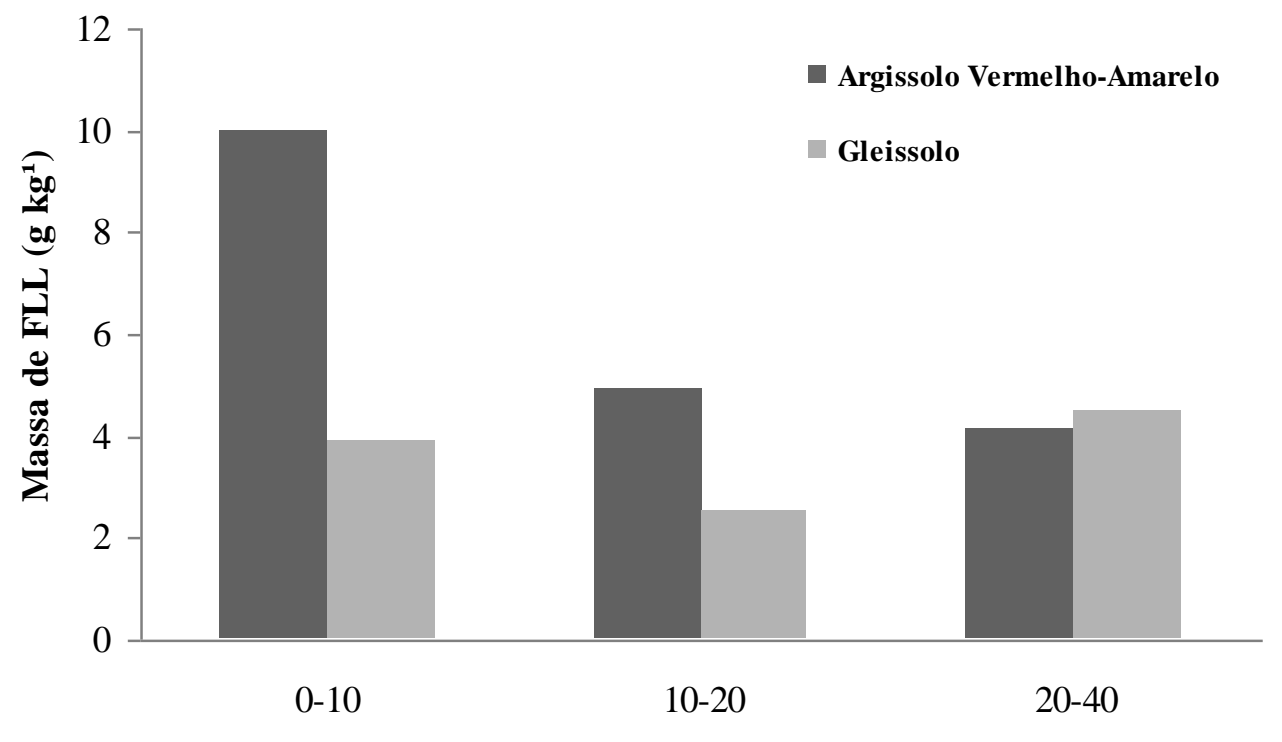

Profundidade (cm)

Figura 6. Massa de fração leve livre (FLL) numa topossequência sob cobertura vegetal de pastagens de Brachiaria humidicola, em Seropédica (RJ)

Outro fator que pode estar relacionado à perda de $\mathrm{N}_{2} \mathrm{O}$ é a presença de agregados no solo. A Figura 7 mostra o diâmetro médio ponderado (DMP) dos agregados do solo Argissolo Vermelho-Amarelo e Gleissolo, nas profundidades de 0-5 e 5-10 $\mathrm{cm}$. Observa-se que o Argissolo Vermelho-Amarelo possui um maior DMP em ambas as profundidades avaliadas $(p<0,05)$. 


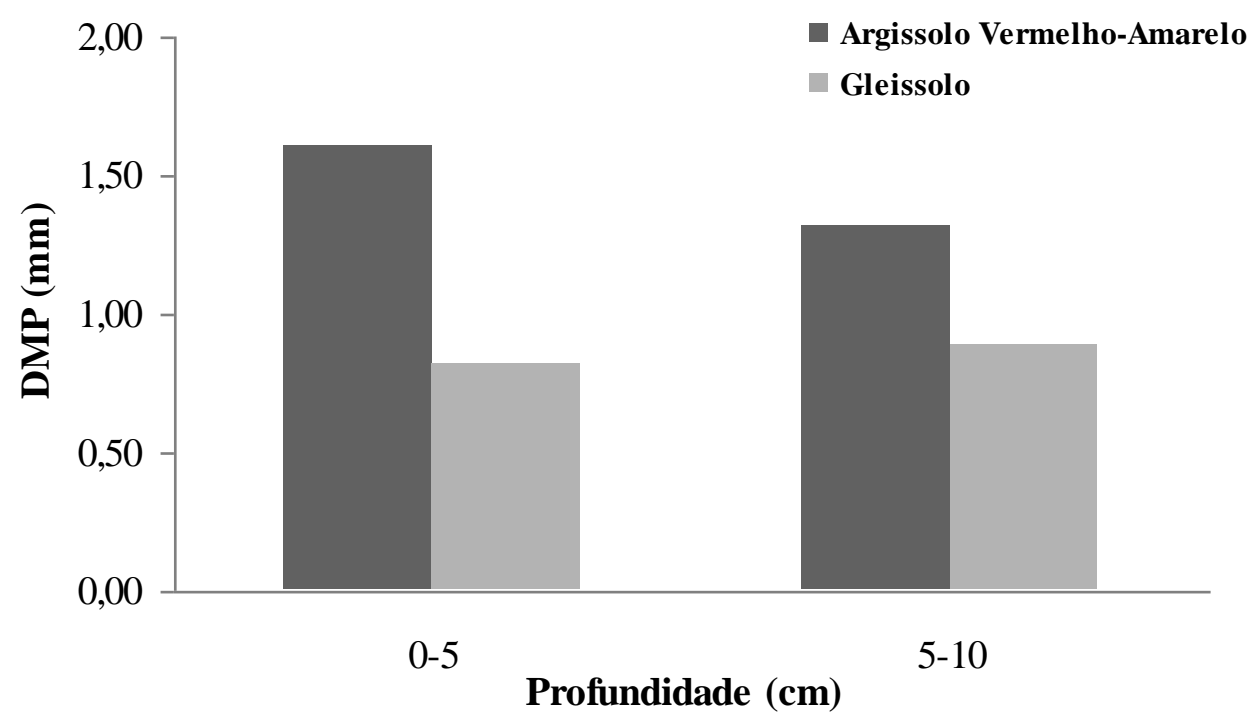

Figura 7. Diâmetro médio ponderado (DMP) numa topossequência com Argissolo VermelhoAmarelo e Gleissolo sob cobertura vegetal de pastagens de Brachiaria humidicola, em Seropédica (RJ)

Para que ocorra a agregação do solo é necessário que haja a floculação das partículas do solo e a cimentação. O principal agente cimentante no solo é a matéria orgânica. Os trabalhos na literatura mostram que os solos que possuem grandes quantidades de agregados estáveis maiores que $2,0 \mathrm{~mm}$, possuem também maiores teores de matéria orgânica. ${ }^{43-45}$ Essa relação entre a agregação do solo e o teor de matéria orgânica também pode ser constatada nesse trabalho onde, no Argissolo VermelhoAmarelo foi observada uma maior entrada de matéria orgânica do solo, através de um maior aporte de FLL, e um maior DMP (Figuras 6 e 7). No interior dos agregados pode haver a oclusão de matéria orgânica, que fica protegida fisicamente da mineralização. É criado um ambiente de menor difusão de oxigênio e de maior conteúdo de água, promovendo a formação de sítios de anaerobiose no solo que pode explicar as maiores perdas de $\mathrm{N}_{2} \mathrm{O}$ observada no Argissolo Vermelho-Amarelo. ${ }^{43-45}$

Os sistemas de manejo do solo que adicionam mais carbono, como por exemplo, o cultivo mínimo (CM), o plantio direto (PD) e a integração lavoura-pecuária-floresta (iLPF) apresentam maiores e mais estáveis agregados quando comparados com o preparo convencional (PC). Num estudo realizado no Sul do país, o solo manejado sob o sistema PD apresentou mais agregado estável e carbono orgânico nos agregados e no solo quando comparado com o manejo PC. ${ }^{46}$ Os autores também observaram, em condições de laboratório, maiores taxas de emissão de gás carbônico $\left(\mathrm{CO}_{2}\right)$ no $\mathrm{PD}$ quando comparado ao $\mathrm{PC}$, devido ao maior conteúdo de $\mathrm{C}$. Isso demonstra que manejos conservacionistas, como o PD, acumulam mais $C$ no solo pela proteção do mesmo nos macroagregados do solo.

Em Paranavaí (PR), foi a avaliado o efeito de diferentes aportes de matéria orgânica bruta, via deposição de palhada da cana-deaçúcar, e observou-se que a aplicação de 50 $\%$ de palha sobre o solo apresentou um maior potencial de armazenar $\mathrm{C}$ em agregados de maior diâmetro (4-2 e 2-1 mm) que a retirada de toda a palha $(0 \%){ }^{34}$ Estudos têm comprovado a importância do aporte de resíduos vegetais sobre o solo no sequestro e armazenamento de C. ${ }^{46-48}$

Outro fator que também pode explicar maiores perdas de óxido nitroso do solo para a atmosfera é o conteúdo de água no solo. $\mathrm{O}$ 
aumento da umidade do solo no terceiro dia de monitoramento após a ocorrência da precipitação pode ter influenciado diretamente as emissões de $\mathrm{N}_{2} \mathrm{O}$, através da formação de sítios de anaerobiose nos agregados do solo. ${ }^{48}$ Nesse dia houve um maior pico de emissão de $\mathrm{N}_{2} \mathrm{O}$, o espaço poroso saturado por água (EPSA) do Argissolo Vermelho-Amarelo estava em, aproximadamente, $80 \%$.

Estudos mostram que o EPSA regula os processos do ciclo do nitrogênio. Quando o EPSA está abaixo de $60 \%$ o principal processo de formação de $\mathrm{N}_{2} \mathrm{O}$ é a nitrificação,

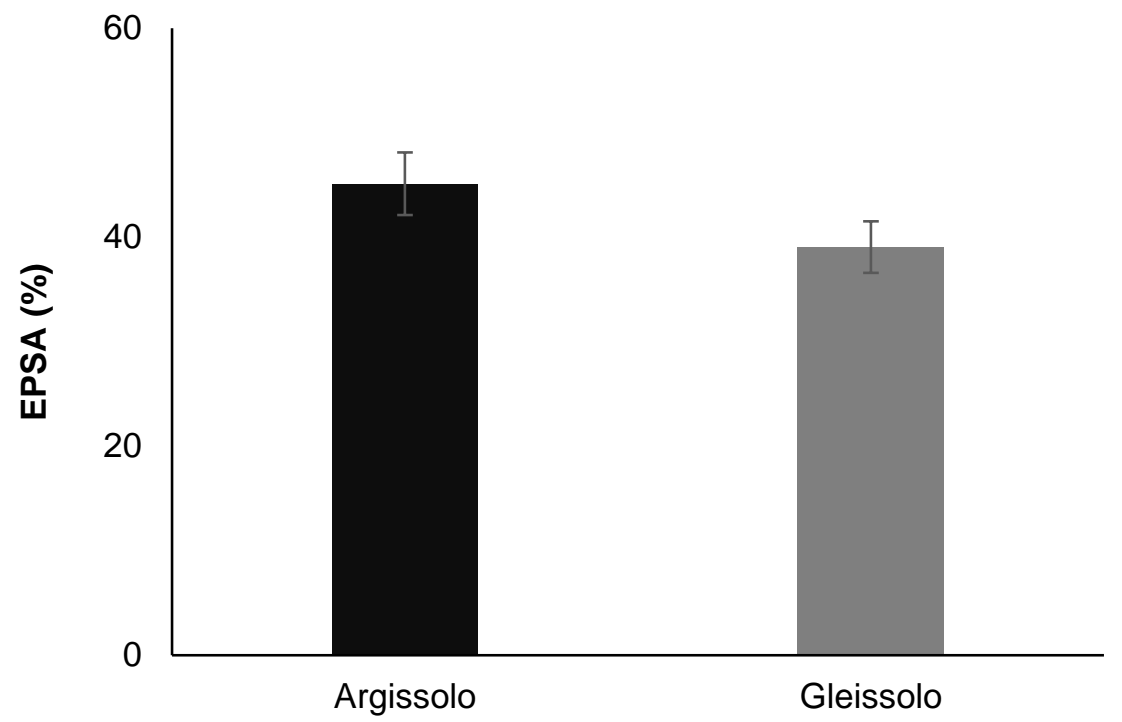

Figura 8. Espaço Poroso Saturado por Água (EPSA) (\%), na camada de $10 \mathrm{~cm}$ do solo. As barras verticais representam o erro padrão da média $(n=11)$

Na Figura 9 são apresentados os valores de emissão acumulada de $\mathrm{N}_{2} \mathrm{O}$, em ambos os tratamentos, durante o período de onze dias de monitoramento, na estação de verão. Nota-se que o Argissolo Vermelho-Amarelo apresentou uma maior emissão acumulada de $\mathrm{N}_{2} \mathrm{O}$ alcançando valor de, aproximadamente, 43,3 g N-N $\mathrm{N}_{2} \mathrm{O} \mathrm{ha}^{-1} \mathrm{dia}^{-1}$, diferindo estatisticamente $(p<0,10)$ do Gleissolo que apresentou um acúmulo entre $60-80 \%$ a desnitrificação é o principal processo e quando o EPSA ultrapassa $80 \%$ (solo saturado) há formação de $\mathrm{N}_{2}$, o qual retorna para atmosfera fechando o ciclo do nitrogênio no sistema solo-plantaatmosfera. ${ }^{50}$

A Figura 8 apresenta o EPSA (\%) médio dos onze dias de monitoramento. Observa-se que, em ambos os tratamentos, a média do EPSA foi menor que $60 \%$, não diferindo estatisticamente $(p<0,05)$, esse resultado evidencia que a principal via de formação do $\mathrm{N}_{2} \mathrm{O}$ foi à nitrificação. 


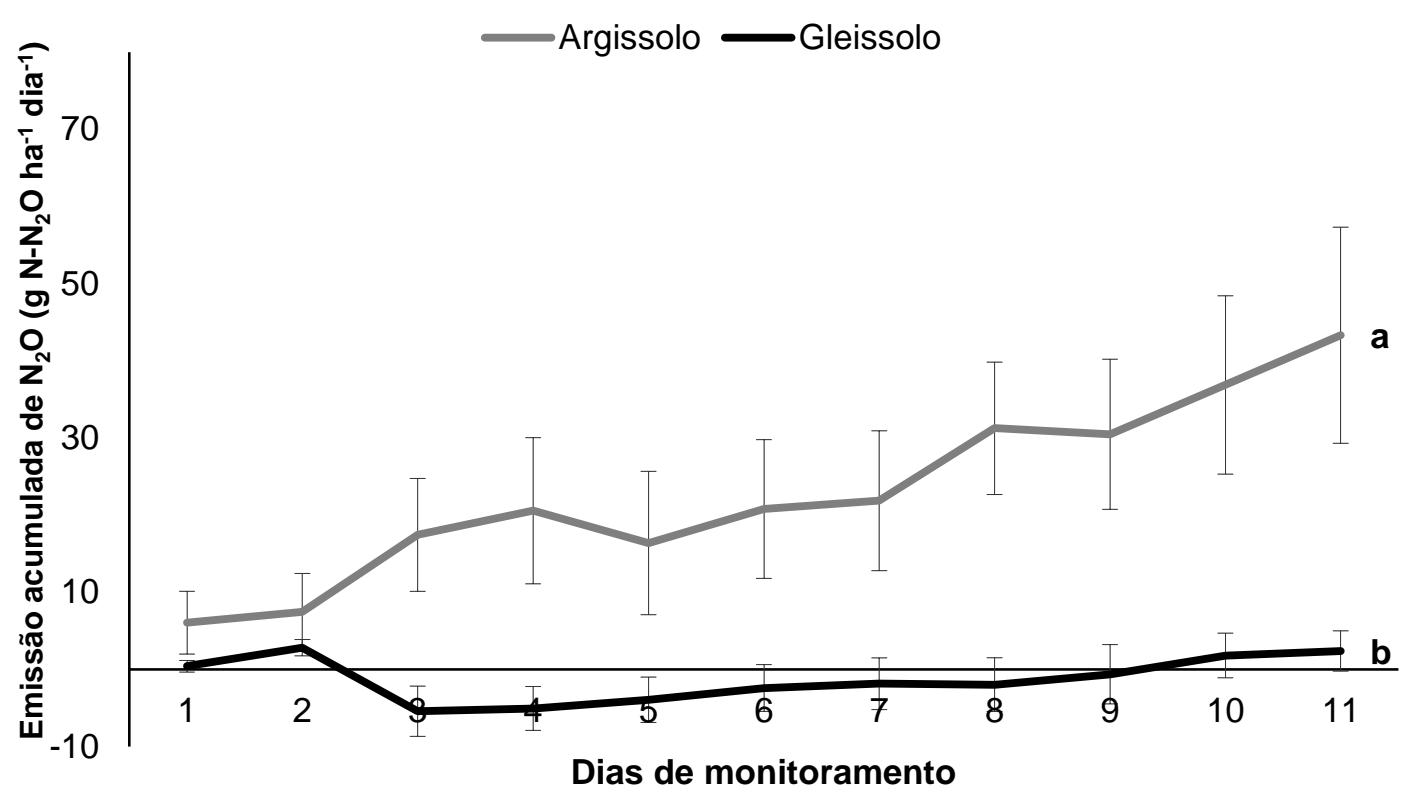

Figura 9. Emissão acumulada de $\mathrm{N}_{2} \mathrm{O}\left(\mathrm{g} \mathrm{N}-\mathrm{N}_{2} \mathrm{O} \mathrm{ha}^{-1} \mathrm{dia}^{-1}\right)$ no período de onze dias de monitoramento

Nos solos de textura fina e em condições de má drenagem são observados maiores fluxos de óxido nitroso em comparação a solos de textura fina e de boa drenagem. ${ }^{51}$ Esse comportamento não foi observado nos solos Argissolo Vermelho-Amarelo e Gleissolo, ambos de textura arenosa onde, em condições de má drenagem, na posição mais baixa do relevo, foi observado menor fluxo de $\mathrm{N}_{2} \mathrm{O}$. Adicionalmente, um dos fatores que governam a emissão é o conteúdo de carbono prontamente disponível para os microrganismos, o qual foi observado uma menor quantidade no Gleissolo em relação ao Argissolo Vermelho-Amarelo.

É necessário um maior período de monitoramento das emissões de $\mathrm{N}_{2} \mathrm{O}$ nas diferentes épocas do ano, assim como, uma avaliação dos diferentes manejos de pastagens (produtiva e degradada) na emissão de $\mathrm{N}_{2} \mathrm{O}$. Também se faz necessário a quantificação dos fatores de emissão para urina e fezes (fonte de $\mathrm{N}$ ) quando os mesmos são depositados pelo gado nessas pastagens.

\section{Conclusões}

O Argissolo Vermelho-Amarelo tem um potencial de emitir óxido nitroso dezoito vezes maior que o Gleissolo. Esse gás tem um potencial de aquecimento global, aproximadamente, 300 vezes superior ao do gás carbônico. Os Argissolos são a segunda classe de solo de maior expressão no território brasileiro, sendo esses solos amplamente utilizados com cobertura de pastagem. A mudança no uso da terra, tais como, a retirada da mata e a entrada de pasto seguida da agricultura, é o principal fator responsável pela emissão de GEE do solo para a atmosfera no país.

A emissão de óxido nitroso foi influenciada pelas diferenças nas classes de solos (Argissolo Vermelho-Amarelo e Gleissolo), pela drenagem e pela topografia. Porém, os mecanismos mais importantes relacionados às perdas de $\mathrm{N}_{2} \mathrm{O}$ para atmosfera são os atributos físicos e químicos do solo. $O$ espaço poroso saturado por água, a fração leve livre da matéria orgânica e a 
agregação do solo são atributos físicos e químicos que podem estar contribuindo na regulação das vias de perda de $\mathrm{N}$ por nitrificação.

\section{Agradecimentos}

À Fundação Carlos Chagas Filho de Amparo à Pesquisa do Estado do Rio de Janeiro (FAPERJ) e a Embrapa Agrobiologia pelo apoio financeiro e técnico.

\section{Referências Bibliográficas}

${ }^{1}$ Mazoyer, M.; Roudart, L.; História das agriculturas no mundo: Do neolítico à crise contemporânea. 1a.ed., UNESP: São Paulo, 2010.

${ }^{2}$ Steffen, W.; Broadgate, W.; Deutsch, L.; Gaffney, O.; Ludwig, C. The trajectory of the Anthropocene: The great acceleration. The Anthropocene Review 2015, 2, 81. [CrossRef]

${ }^{3}$ Relatório das Nações Unidas. The 2017 Revision of World Population Prospects. $2017 . \quad$ Disponível em: $<$ https://esa.un.org/unpd/wpp/>. Acesso em: 3 junho 2018.

${ }^{4}$ Silva, C. M.; Arbilla, G. Antropoceno: Os Desafios de um Novo Mundo. Revista Virtual de Química 2018, 10, 1619. [CrossRef]

${ }^{5}$ Cardoso, A. S; Berndt, A.; Leytern, A.; Alves, B. J. R; Carvalho, I. N. O.; Soares, L. H. B.; Urquiaga, S.; Boddey, R. M. Impact of the intensification of beef product in Brazil on greenhouse gas emissions and land use. Agricultural Systems 2016, 143, 86. [CrossRef]

${ }^{6}$ IBGE - Instituto Brasileiro de Geografia e Estatística, Censo Agropecuário 2006. Comunicado social, Dezembro de 2007. Disponível em:
$<$ www.ibge.gov.br/home/presidencia/noticia s >. Acesso em: 15 junho 2018.

${ }^{7}$ Cottle, D. J.; Nolan, J. V.; Wiedemann, S. G. Ruminant enteric methane mitigation: a review. Animal Production Science 2011, 51, 491. [CrossRef]

${ }^{8}$ MCTIC- Ministério da Ciência, Tecnologia, Inovações e Comunicações. Disponível em:

$<$ http://sirene.mcti.gov.br/gases-porsubsetor >. Acesso em 16 de maio de 2018.

${ }^{9}$ IPCC - Intergovernmental Panel on Climate Change 2006. IPCC Guidelines for National Greenhouse Gas Inventories. Chapter 10: Emissions from livestock and Manure Management. [Link]

${ }^{10}$ Demarchi, J. J. A. A.; Lourenço, A. J.; Manella, M. Q.; Alleoni, G. F.; Friguetto, R. S.; Primavesi, O.; Lima, M. A.; Abstract in IX World Conference on Animal Production and XVIII Reunião Latinoamericana de Produção Animal, Porto Alegre, Rio Grande do Sul, Brasil, 2003. [Link]

${ }^{11}$ Berchielli, T. T.; Messana, J. D.; Canesin, R.C. Produção de metano entérico em pastagens tropicais. Revista Brasileira de Saúde e Produção Animal 2012, 13, 4. [CrossRef]

${ }^{12}$ Almeida, R. F.; Naves, E. R.; Silveira, C. H. Emissão de óxido nitroso em solos com diferentes usos e manejos: uma revisão. Revista em Agronegócio e Meio Ambiente 2015, 8, 441. [CrossRef]

${ }^{13}$ Signor, D.; Cerri, C. E. P.; Conant, R. $\mathrm{N}_{2} \mathrm{O}$ emissions due to nitrogen fertilizer applications in two regions of sugarcane cultivation in Brazil. Environmental Research Letters 2013, 8, 9. [CrossRef]

14 Jantalia, C. P.; Zotarelli, L.; Santos, H. P.; Torres, E.; Urquiaga, S.; Boddey, R. M.; Alves, B. J. R. Em Manejo dos sistemas agrícolas: impacto no sequestro de $C$ e nas emissões de gases de efeito estufa; Alves, B. J. R.; Urquiaga, S.; Aita, C.; Boddey, R. M.; Jantalia, C. P.; Camargo, F. A. O., eds. Genesis: Porto Alegre, 2006, cap.4. 
${ }^{15}$ Smith, K. A.; Ball, T.; Conen, F.; Dobbie, K. E.; Massheder, J.; Rey, A. Exchange of greenhouse gases between soil and atmosphere: interactions of soil physical factors and biological processes. European Journal of Soil Science 2003, 54, 779. [CrossRef]

${ }^{16}$ Bouwman, A. F. Nitrogen oxides and tropical agriculture. Nature 1998, 392, 866. [CrossRef]

${ }^{17}$ Rodrigues, R. A. R.; de Mello, W. Z.; da Conceição, M. C. G.; de Souza, P. A.; Silva, J. J. N. Dinâmica do Nitrogênio em Sistemas Agrícolas e Florestais Tropicais e seu impacto na Mudança do Clima. Revista Virtual de Química 2017, 9, 1868. [Link]

${ }^{18}$ Lopes, I. M.; Pinheiro, E. F. M.; Lima, E.; Ceddia, M. B.; Campos, D. V. B, Alves, B. J. R. Emissões de $\mathrm{N}_{2} \mathrm{O}$ em solos sob cultivo de cana-de-açúcar no bioma Mata Atlântica: efeito dos sistemas de colheita e da adubação com vinhaça. Revista Virtual de Química 2017, 9, 1930. [CrossRef]

${ }^{19}$ Cantarella, H. Em Fertilidade do Solo; Novais, R. F.; Venegas, V. H. A.; Barros, N. F.; Fontes, R. L. F.; Cantarutti, R. B.; Neves, J. C. L., eds.; Sociedade Brasileira de Ciência do Solo: Viçosa, 2007, cap.7.

${ }^{20}$ Moreira, F. M. S.; Siqueira, J. 0. Microbiologia e bioquímica do solo. 2a. ed. UFLA: Lavras, 2006.

${ }^{21}$ Bremmer, J. M. Sources of nitrous oxide in soils. Nutrient Cycling in Agroecosystems 1997, 49, 7. [CrossRef]

${ }^{22}$ Snyder, C. S.; Bruulsema, T. W.; Jensen, T. L.; Fixan, P. E. Review of greenhouse gas emissions form cropping production systems and fertilizer management effects. Agriculture Ecosystems and Environment 2009, 133, 247. [CrossRef]

${ }^{23}$ Signor, D.; Dissertação de Mestrado, Escola Superior de Agricultura "Luiz de Queiroz", Universidade de São Paulo, Brasil, 2010. [Link]

${ }^{24}$ Signor, D.; Pissioni, L. L. M.; Cerri, C. E. P. Emissões de gases de efeito estufa pela deposição de palha de cana-de-açúcar sobre o solo. Bragantia 2014,73, 113. [CrossRef]

${ }^{25}$ Boeckx, P.; Van Cleemput, O. Estimates of $\mathrm{N}_{2} \mathrm{O}$ and $\mathrm{CH}_{4}$ fluxes from agricultural lands in various regions in Europe. Nutrient Cycling in Agroecosystems 2001, 60, 35. [CrossRef]

${ }^{26}$ Santos, H.G.; Fidalgo, E.C.C.; Áglio, M.L.D. Árvore do Conhecimento :Arroz- Solo. Disponível

em: $<$ http://www.agencia.cnptia.embrapa.br/ gestor/arroz/arvore/CONT000fesi63xh02wx5 eo0y53mhyx67oxh3.html>. Acesso em: 10 junho 2018.

27 Santos, H. G.; Jacomine, P. K. T.; Anjos, L. H. C.; Oliveira, V. A.; Oliveira, J. B.; Coelho, M. R.; Lumbreras, J. F.; Cunha, T. J. F. (Ed.). Sistema brasileiro de classificação de solos. 3a ed. Embrapa: Brasília, 2013.

${ }^{28}$ Embrapa - Empresa Brasileira de Pesquisa Agropecuária. Manual de métodos de análise de solo. 2a ed., Revista Atual: Rio de Janeiro, 1997.

${ }^{29}$ Paul, E. A.; Clark, F. E. Soil microbiology and biochemistry. 2nd ed. Academic Press: California, 1996.

${ }^{30}$ Sohi, S.; Mahieu, N.; Arah, J. R. M.; Powlson, D. S. P.; Madari, B. \& Gaunt, J.L. Procedure for isolating soil organic matter fractions suitable for modeling. Soil Science Society of America Journal 2001, 65, 1121. [CrossRef]

${ }^{31}$ Pinheiro, E. F. M.; Pereira, M. G.; Anjos, L. H. C.; Machado, P. L. O. A. Fracionamento densimétrico da matéria orgânica do solo sob diferentes sistemas de manejo e cobertura vegetal em paty do alferes (RJ). Revista Brasileira de Ciência do Solo 2004, 28, 731. [CrossRef]

${ }^{32}$ Chagas, L. F. B.; Falcão, N. P. S.; Padilha, F. J.; Oliveira, D. M.; Guimarães, R. S.; Campos, D. V. B.; Walverde, E. M.; Ferreira, P. H. Z.; Soares, R. Revista Virtual de Química 2017, 9, 2067. [CrossRef]

${ }^{33}$ Kemper, W.D.; Chepil, W.S. Em Methods of Soil Analysis; Black, C.A. (ed.); American Society of Agronomy: Madison, 1965, cap. 39. 
${ }^{34}$ Lopes, I. M.; Ziviani, M. M.; Pinto, L. A. S.; Pinheiro, E. F. M.; Weber, H.; Pereira, M. G.; Lima, E.; Campos, D. V. B. Agregação e distribuição do carbono nos agregados de Latossolo Vermelho sob diferentes níveis de palhada da cana-de-açúcar em Paranavaí (PR). Revista Virtual de Química 2017, 9, 1930. [CrossRef]

${ }^{35}$ Ferreira, D. F. Sisvar: a Guide for its Bootstrap procedures in multiple comparisons. Ciência e Agrotecnologia 2014, 38, 109. [CrossRef]

${ }^{36}$ Blackmer, A. M.; Bremner, J. M. Potencial of soil as a sink for atmospheric nitrous oxide. Geophysical Research Letters 1976, 3, 739. [CrossRef]

${ }^{37}$ Drury, C. F.; Yang, X. M.; Reynolds, W. D.; Tan, C. S. Influence of crop rotation and aggregate size on carbon dioxide production and denitrification. Soil and Tillage Research 2004, 79, 87. [CrossRef]

${ }^{38}$ Chapuis-Lardy, L.; Wrage, N.; Metay, A.; Chottes, J.; Bernouxs, M. Soils, a sink for $\mathrm{N}_{2} \mathrm{O}$ ? A Review. Global Change Biology 2007, 13, 1. [CrossRef]

${ }^{39}$ Corrêa, R. S.; Madari, B. E.; Carvalho, G. D.; Costa, A. R.; Pereira, A. C. C.; Medeiros, J. C. Fluxos de óxido nitroso e suas relações com atributos físicos e químicos do solo. Pesquisa agropecuária brasileira 2016, 51, 1148. [CrossRef]

${ }^{40}$ Tsuneda, S.; Mikami, M.; Kimochi, Y.; Hirata, A. Effect of salinity on nitrous oxide emission in the biological nitrogen removal process for industrial wastewater. Journal of Hazardous Materials 2005, 119, 93. [CrossRef]

${ }^{41}$ Kampschreur, M. J.; Tan, N. C.; Kleerebezem, R.; Picioreanu, C.; Jetten, M. S; van Loosdrecht, M. C. Effect of dynamic process conditions on nitrogen oxides emission from a nitrifying culture. Environmental Science \& Technology 2008, 42, 429. [CrossRef]

${ }^{42}$ Nogueira, A. K. S.; Rodrigues, R. A. R.; Silva, J. J. N.; Botin, A. A.; Silveira, J. G.; Mombach,
M. A.; Armacolo, N. M.; Romeiro, S. O. Fluxos de óxido nitroso em sistema de integração lavoura-pecuária-floresta. Pesquisa Agropecuária Brasileira 2016, 51, 1156. [CrossRef]

${ }^{43}$ Pinheiro, E. F. M.; Pereira, M. G.; Anjos, L. H. C.; Machado, P. L. O. A. Fracionamento Densimétrico da Matéria Orgânica do Solo sob Diferentes Sistemas de Manejo e Cobertura Vegetal em Paty do Alferes (RJ). Revista Brasileira de Ciência do Solo 2004, 28, 731. [CrossRef]

${ }^{44}$ Denef, K.; Zotarelli, L.; Boddey, R. M.; Six, J. Microaggregate-associated carbon as a diagnostic fraction for management-induced changes in soil organic carbon in two Oxisols. Soil Biology and Biochemistry 2007, 39,1165. [CrossRef]

${ }^{45}$ Loss, A.; Pereira, M. G.; Giácomo, S. G.; Perin, A.; Anjos, L. H. C. Agregação, carbono e nitrogênio em agregados do solo sob plantio direto com integração lavoura-pecuária. Pesquisa Agropecuária Brasileira 2011, 46,1269. [CrossRef]

${ }^{46}$ Jiang, C. M.; Yu, W. T.; Ma, Q.; Xu, Y. G.; Zou, H. Alleviating global warming potential by soil carbon sequestration: A multi-level straw incorporation experiment from a maize cropping system in Northeast China. Soil and Tillage Research 2017, 170, 77. [CrossRef]

${ }^{47}$ Zhao, S.; Li, K.; Zhou, W.; Qiu, S.; Huang, S.; $\mathrm{He}$, P.; Changes in soil microbial community, enzyme activities and organic matter fractions under long-term straw return in north-central China. Agriculture, Ecosystems and Environment 2016, 216, 82. [CrossRef]

${ }^{48}$ Zhu, L.; Hu, N.; Zhang, Z.; Xu, J.; Tao, B.; Meng, Y. Short-term responses of soil organic carbon and carbon pool management index to different annual straw return rates in a rice-wheat cropping system. Catena 2015, 135, 283. [CrossRef]

${ }^{49}$ Barreto, R. C; Beata, M.; Maddock, J.; Torres, E.; Franchinic, J.; Costa, A. R. The impact of soil management on aggregation, carbon stabilization and carbon loss as $\mathrm{CO}_{2}$ in 
the surface layer of a Rhodic Ferralsol in Southern Brazil. Agriculture, Ecosystems \& Environment 2009, 132, 243. [CrossRef]

${ }^{50}$ Dobbie, K. E.; Smith, K. A. Nitrous oxide emission factors for agricultural soils in Great Britain: the impact of soil water-filled pore space and other controlling variables. Global Change Biology 2003, 9, 204. [CrossRef]

${ }^{51}$ Skiba, U.; van Djik, S.; Ball, B.C. The influence of tillage on $\mathrm{NO}$ and $\mathrm{N}_{2} \mathrm{O}$ fluxes under spring and winter barley. Soil Use and Management 2002, 18, 340. [CrossRef] 